\title{
O desafio da atenção integral à saúde da criança
}

\author{
The challenge of integral care for children's health
}

\section{Beatriz Sebben Ojeda ${ }^{a}$}

a Enfermeira. Doutora em Psicologia pela PUCRS. Professora Titular da Escola de Ciências da Saúde da Pontifícia Universidade Católica do Rio Grande do Sul. Porto Alegre, RS, Brasil.

\begin{abstract}
A Atenção Integral à Saúde da Criança tem sido, nas últimas décadas, uma das metas prioritárias da Organização Mundial de Saúde (OMS). Essa proposição decorre do reconhecimento de que a infância é um período de vulnerabilidade e, portanto, a humanidade, em todos os seus segmentos (família, sociedade, estado), é responsável pelo desenvolvimento biopsicossocial desse grupo de modo a garantir que as futuras gerações sejam comprometidas e responsáveis pela promoção de uma sociedade saudável, eticamente competente, solidária e preocupada com a sustentabilidade ambiental planetária.

No Brasil, a Portaria GM/MS no 1.130, de 5 de agosto de 2015, instituiu a Política Nacional de Atenção Integral à Saúde da Criança (PNAISC) que tem como propósito promover e proteger a saúde da criança por meio da atenção e cuidados integrais, desde a gestação até os nove anos de vida, que é o período caracterizado pela OMS, como infância. Há, contudo, a atenção especial para os primeiros dois anos de vida da criança, com o objetivo de reduzir a morbimortalidade e também de promover o desenvolvimento de um ambiente facilitador da vida dessas crianças e das condições dignas de sua existência, corresponsabilizando seus cuidadores, suas famílias e os profissionais responsáveis pela atenção a essas crianças.

Nessa perspectiva, para a efetivação da atenção integral à saúde da criança, é necessária a união de conhecimentos e de práticas requerendo atuação interprofissional nos diferentes níveis de atenção em saúde, e também integração intersetorial. Portanto, as ações e serviços articulados em rede de atenção qualificam e potencializam os recursos disponíveis, de forma adequada e resolutiva, para a melhor qualidade de vida dessas crianças.

Os artigos apresentados nesta edição expressam diferentes perspectivas e conhecimentos acerca da saúde da criança e revelam a importância da aproximação desses olhares para a concretização de práticas mais integrais, menos fragmentadas e mais resolutivas para as crianças, suas famílias e a sociedade.
\end{abstract}

Boa leitura a todos! 